\title{
The established risk of prostate cancer comorbidity in BRCA1/2 mutation carriers: where is the clinically relevant hotspot for prostate cancer?
}

\author{
Takashi Matsumoto, Masaki Shiota^ \\ Department of Urology, Graduate School of Medical Sciences, Kyushu University, Higashi-Ku, Fukuoka, Japan \\ Correspondence to: Masaki Shiota. Department of Urology, Graduate School of Medical Sciences, Kyushu University, 3-1-1, Maidashi, Higashi-Ku, \\ Fukuoka 812-8582, Japan. Email: shiota@uro.med.kyushu-u.ac.jp.
}

Submitted Apr 16, 2020. Accepted for publication May 26, 2020.

doi: $10.21037 /$ tau-20-866

View this article at: http://dx.doi.org/10.21037/tau-20-866

$B R C A 2$ carriers have a higher risk of prostate cancer (PCa), especially of an aggressive pattern, according to new data from a prospective cohort study published by Nyberg et al. in European Urology (1). Two prospective reports on PCa risks for $B R C A 1 / 2$ carriers have previously been published $(2,3)$. However, these were limited in that the $95 \%$ confidence interval (CI) was wide and absolute risk was not represented, owing to small sample sizes. The aim of the current EMBRACE study (Epidemiological Study of Familial Breast Cancer; http://ccge.medschl.cam. ac.uk/embrace/) is to create a register of families carrying $B R C A 1 / 2$ mutations and to obtain prospective estimates of cancer incidence for these carriers. This cohort study including BRCA1 $(\mathrm{n}=376)$ and BRCA2 $(\mathrm{n}=477)$ mutation carriers started in 1998 across the UK and Ireland. All participants were male with no PCa diagnosis at recruitment. Their median follow-up times were 5.9 and 5.3 years for UK and Irish patients, respectively.

Nyberg et al. examined the relationship between BRCA2 mutation carriers and PCa risk or clinical grade. Twentysix BRCA2 carriers were diagnosed with PCa during followup and had a higher risk [standardized incidence rate (SIR), 4.45; 95\% CI, 2.99-6.61] compared with population in the UK. Notably, the risk at age $<65$ years was also high (SIR, 3.99; 95\% CI, 1.88-8.49). Moreover, BRCA2 mutation carriers with a family history of PCa showed a prominently higher risk (SIR, 7.31; 95\% CI, 3.40-15.7). $B R C A 2$ mutation carriers also had a higher Gleason score $(\geq 7)$. However, BRCA1 mutation carriers were associated with a more modest incidence risk of PCa. Consistently, a meta-analysis by $\mathrm{Oh}$ et al. that summarized eight cohort, seven case-control, four case series, 28 frequencies, and 11 survival studies, found that $B R C A 2$ mutations were associated with a greater risk of $\mathrm{PCa}$ [odds ratio (OR), 2.64; 95\% CI, 2.03-3.47] than BRCA1 mutations (OR, 1.35; 95\% CI, 1.03-1.76) (4).

Intriguingly, BRCA1 mutations are more common in ovarian and breast cancer than $B R C A 2$ mutations. In fact, the percentages of patients with $B R C A 1 / 2$ alterations differ in various cancer types (5). BRCA1 and BRCA2 share a common pathway of genome repair. To maintain genomic integrity, DNA damage response (DDR) genes mediate cellular signals against double-strand breaks caused by genotoxic stresses such as ionizing radiation and other genotoxic compounds. The DDR also includes the activation of checkpoints that delay the cell cycle at G1/S or G2/M, enabling sufficient time for DNA repair not to be transmitted to subsequent generations.

Two systems are employed to repair double-strand breaks, homologous recombination (HR) and non-homologous end-joining (NHEJ). BRCA1 and BRCA2 are associated with $\mathrm{HR}$ which is mostly error-free in their roles as tumor suppressors. However, BRCA1/2 genes function differently in terms of DDR (6). BRCA1 has functions in both checkpoint activation and DNA repair, whereas BRCA2 is a mediator of the core mechanism of HR. Mutations in both BRCA1 and

$\wedge$ ORCID: 0000-0002-3306-4858. 
BRCA2 lead to HR deficiency (HRD) and compensatory repair of double-strand breaks by NHEJ, which is errorprone repair mechanism compared with HR. Thus, repairerrors caused by HRD by BRCA1/2 mutations accumulate in the genome and increase the rate of carcinogenesis; thus, $B R C A 1 / 2$ mutation carriers have an increased risk of $\mathrm{PCa}$ at a younger age. To account for tissue-specific roles of BRCA1 and BRCA2 mutations, the interactions of BRCAs and steroid receptors including estrogen receptor and progesterone receptor were suggested (7). However, the mechanism by which $B R C A 2$ is a higher risk factor for PCa compared with $B R C A 1$ remains unclear and requires further study.

The increased risk of cancer death not only reflects increased carcinogenesis, but also the onset of a clinically high grade of cancer at an early age. Therefore, BRCA1/2 mutation carriers have worse outcomes than non-carriers with respect to treatment for locally-advanced PCa. Castro et al. reported that BRCA2 mutations are an independent prognostic factor for cause-specific survival in all stages of PCa including localized disease (8). They also reported that BRCA1/2 mutation carriers have worse metastatic-free survival and cause-specific survival after radical treatment such as radical prostatectomy or external beam radiation therapy (9). The controversies regarding prognosis following treatment with non-curative therapy (10) indicate that further investigations into BRCA1/2 mutations and prognosis in PCa are required.

Nyberg et al. investigated the association between the ovarian cancer cluster region (OCCR) and PCa risk. OCCR is a well-known region which is strongly associated with ovarian cancer risk (11). This study reported that $B R C A 2$ mutations located in positions c.2831 and c.6401 of the OCCR were less associated with PCa risk (SIR, 2.46; 95\% CI, 1.07-5.64) than other regions (SIR, 5.88; 95\% CI, 3.759.22 ), suggesting that mutations outside the OCCR play an important role in the $\mathrm{PCa}$ incidence. This is consistent with breast cancer findings, in which BRCA1/2 mutations outside the OCCR were associated with a significantly higher breast cancer risk compared with mutations within the OCCR (12). However, so far, the association between BRCA2 mutations in the OCCR and PCa risk is controversial. Lubinski et al. reported that BRCA2 carriers of the 6174delT mutation were less likely to have a family member with $\mathrm{PCa}(\mathrm{OR}, 0.62$; $\mathrm{P}=0.04)$ than those without mutations (13). In contrast, Moran et al. showed that a higher risk of $\mathrm{PCa}(\mathrm{HR}, 2.92$; $95 \%$ CI, 1.54-5.54) was found in males with mutations in the BRCA2 OCCR region than in other regions (14).
To resolve these discrepancies, additional studies into the relationship between the OCCR and PCa risks as well as prognosis are required.

Finally, BRCA1/2 mutations have an important clinical impact because precision medicine is considered for carriers. Page et al. assessed the utility of prostate-specific antigen (PSA) screening in an IMPACT study for mean aged 40-60 years with or without BRCA1/2 mutations (15). In an interim report 3 years after screening began, $B R C A 2$ mutation carriers were associated with a higher incidence of $\mathrm{PCa}$, younger age of diagnosis, and more clinically significant tumors compared with men with no BRCA1/2 mutations. Therefore, they concluded that PSA screening for men with $B R C A 2$ mutations is recommended. In terms of treatment, Pomerantz et al. reported that BRCA2 mutation carriers responded favorably to platinum-based chemotherapy normally used in the treatment of breast and ovarian cancers (16). Additionally, poly adenosine diphosphate (ADP)-ribose polymerase (PARP) inhibitors are a novel and promising drug for PCa patients carrying BRCA1/2 mutations. Single strand annealing by PARP is an alternative pathway for DNA repair. PARP is essential for the survival of cells with HRD, and further inhibition of PARP function in such cells renders DDR impossible leading to cell death. Thus, the confirmation of BRCA1/2 mutations is important for genomic medicine.

\section{Acknowledgments}

We thank Sarah Williams, PhD, from Edanz Group (www. edanzediting.com) for editing a draft of this manuscript.

Funding: None.

\section{Footnote}

Provenance and Peer review: This article was commissioned by the editorial office, Translational Andrology and Urology. The article did not undergo external peer review.

Conflicts of Interest: Both authors have completed the ICMJE uniform disclosure form (available at http://dx.doi. org/10.21037/tau-20-866). MS reports personal fees from AstraZeneca, personal fees from Takeda Pharmaceutical. TM has no other conflicts of interest to declare.

Ethical Statement: The authors are accountable for all aspects of the work in ensuring that questions related to the accuracy or integrity of any part of the work are 
appropriately investigated and resolved.

Open Access Statement: This is an Open Access article distributed in accordance with the Creative Commons Attribution-NonCommercial-NoDerivs 4.0 International License (CC BY-NC-ND 4.0), which permits the noncommercial replication and distribution of the article with the strict proviso that no changes or edits are made and the original work is properly cited (including links to both the formal publication through the relevant DOI and the license). See: https://creativecommons.org/licenses/by-nc-nd/4.0/.

\section{References}

1. Nyberg T, Frost D, Barrowdale D, et al. Prostate cancer risks for male BRCA1 and BRCA2 mutation carriers: a prospective cohort study. Eur Urol 2020;77:24-35.

2. Mersch J, Jackson MA, Park M, et al. Cancers associated with BRCA1 and BRCA2 mutations other than breast and ovarian. Cancer 2015;121:269-75.

3. Laitman Y, Keinan Boker L, Liphsitz I, et al. Cancer risks in Jewish male BRCA1 and BRCA2 mutation carriers. Breast Cancer Res Treat 2015;150:631-5.

4. Oh M, Alkhushaym N, Fallatah S, et al. The association of BRCA1 and BRCA2 mutations with prostate cancer risk, frequency, and mortality: a meta-analysis. Prostate 2019;79:880-95.

5. Jonsson P, Bandlamudi C, Cheng ML, et al. Tumour lineage shapes BRCA-mediated phenotypes. Nature 2019;571:576-9.

6. Roy R, Chun J, Powell SN. BRCA1 and BRCA2: different roles in a common pathway of genome protection. Nat Rev Cancer 2011;12:68-78.

7. Gorodetska I, Kozeretska I, Dubrovska A. BRCA genes:

Cite this article as: Matsumoto T, Shiota $M$. The established risk of prostate cancer comorbidity in BRCA1/2 mutation carriers: where is the clinically relevant hotspot for prostate cancer? Transl Androl Urol 2020;9(5):2289-2291. doi:10.21037/ tau-20-866 the role in genome stability, cancer stemness and therapy resistance. J Cancer 2019;10:2109-27.

8. Castro E, Goh C, Olmos D, et al. Germline BRCA mutations are associated with higher risk of nodal involvement, distant metastasis, and poor survival outcomes in prostate cancer. J Clin Oncol 2013;31:1748-57.

9. Castro E, Goh C, Leongamornlert D, et al. Effect of BRCA mutations on metastatic relapse and cause-specific survival after radical treatment for localised prostate cancer. Eur Urol 2015;68:186-93.

10. Warner EW, Yip SM, Chi KN, et al. DNA repair defects in prostate cancer: impact for screening, prognostication and treatment. BJU Int 2019;123:769-76.

11. Thompson D, Easton D, Breast Cancer Linkage Consortium. Variation in cancer risks, by mutation position, in BRCA2 mutation carriers. Am J Hum Genet 2001;68:410-9.

12. Kuchenbaecker KB, Hopper JL, Barnes DR, et al. Risks of breast, ovarian, and contralateral breast cancer for BRCA1 and BRCA2 mutation carriers. JAMA 2017;317:2402-16.

13. Lubinski J, Phelan CM, Ghadirian P, et al. Cancer variation associated with the position of the mutation in the BRCA2 gene. Fam Cancer 2004;3:1-10.

14. Moran A, O'Hara C, Khan S, et al. Risk of cancer other than breast or ovarian in individuals with BRCA1 and BRCA2 mutations. Fam Cancer 2012;11:235-42.

15. Page EC, Bancroft EK, Brook MN, et al. Interim results from the IMPACT study: evidence for prostate-specific antigen screening in BRCA2 mutation carriers. Eur Urol 2019;76:831-42.

16. Pomerantz MM, Spisák S, Jia L, et al. The association between germline BRCA2 variants and sensitivity to platinum-based chemotherapy among men with metastatic prostate cancer. Cancer 2017;123:3532-9. 